\title{
Existem pacientes que usam mal os aparelhos, ou são os aparelhos que não se adequam aos pacientes?
}

\section{A interpretação dos resultados de artigos}

Nos primeiros anos de minha vida ortodôntica, ouvi certas vezes comentários sobre o comportamento dos pacientes em tratamento. Os comentários tratavam da cooperação no uso do aparelho ortodôntico em si ou dos seus acessórios, tais como elásticos intermaxilares, extrabucais, etc. Eram frases pronunciadas com um tom reprovatório: "esse paciente é péssimo, não usa o extrabucal", ou "não tem jeito, ela não usa o aparelho móvel". Aqui, então, chego ao ponto nevrálgico desse editorial. Existem pacientes que usam mal os aparelhos, ou são os aparelhos que não se adequam aos pacientes?

Essa questão tem uma profunda raiz no método científico e no design de diferentes ensaios clínicos, bem como na leitura e compreensão de artigos de pesquisa. Para ilustrá-la, imaginem o cenário hipotético a seguir.

Um estudo é realizado para comparar a eficácia de dois diferentes protocolos de tratamento. Um total de 300 pacientes é envolvido na pesquisa e distribuído aleatoriamente em três grupos: 100 pacientes para o tratamento A, 100 para o B e 100 em um grupo controle. Esses tratamentos poderiam ser, por exemplo, (A) novo aparelho para correção da Classe II e (B) aparelho extrabucal. Nesse estudo, 82 pacientes concluíram o tratamento no grupo $A$ (novo aparelho) e 93 no grupo B (extrabucal). Os resultados hipotéticos, excluindo o grupo controle, estão agrupados na tabela 1 .

Os resultados de nosso estudo hipotético apresentam taxas de sucesso que diferiram entre si. O tratamento A (novo aparelho) teve uma taxa de sucesso de $97,5 \%$, enquanto o tratamento B (extrabucal) teve uma taxa de sucesso de 92,5\%. Agora vem a pergunta intrigante: Qual o melhor tratamento, frente a esses resultados?

A resposta é clara. O tratamento $B$ (extrabucal), com $92,5 \%$ de sucesso, foi, a princípio, MELHOR que o A (novo aparelho), com 97,5\% de sucesso. Isso mesmo, o tratamento com menor taxa de sucesso foi o melhor tratamento para a Classe II. Por quê?

$\mathrm{O}$ número de indivíduos que terminaram o tratamento nos dois grupos foi diferente. Ele foi menor no tratamento A (novo aparelho) do que no tratamento B (extrabucal). Há relevante razão para considerarmos essa diferença como parte dos resultados do tratamento. Ou seja, mais pessoas desistem do novo aparelho porque ele é muito desagradável esteticamente, ou muito incômodo, ou possui alguma qualidade negativa que leva a taxas de adesão menores. Esse fato deve ser sempre analisado quando comparamos tratamentos, ou mesmo quando avaliamos séries de casos.

TABELA 1 - Resultados de um estudo hipotético que compara dois tratamentos para a Classe II, utilizando um novo aparelho (A) e o extrabucal (B). Nesse exemplo, há diferença significativa entre os tratamentos.

$\begin{array}{cccc}\text { TRATAMENTO* } & \begin{array}{c}\text { SUCESSO } \\ \mathrm{N}(\%)\end{array} & \begin{array}{c}\text { INSUCESSO } \\ \mathrm{N}(\%)\end{array} & \text { TOTAL } \\ \begin{array}{c}\text { A } \\ \text { (novo aparelho) }\end{array} & 80(97,5) & 2(2,5) & 82(100) \\ \begin{array}{c}\text { B } \\ \text { (extrabucal) }\end{array} & 86(92,5) & 7(7,5) & 93(100)\end{array}$

* Há diferença estatisticamente significativa entre os tratamentos hipotéticos A e B. 
Vamos interpor outro exemplo. Digamos que os mesmos resultados foram encontrados por um centro de oncologia quando comparava dois quimioterápicos diferentes para o tratamento de um tipo de câncer. O grupo com maior desistência provavelmente utilizou uma droga que leva a mais efeitos colaterais ou complicações que o outro. Consequentemente, possui maiores taxas de desistência.

Se ninguém é mau utilizador de quimioterapia, por que alguém seria mau utilizador de extrabucal ou outro aparelho? Na verdade, não são - acontece que os tratamentos acarretam diferentes respostas nos pacientes. Por exemplo, muitos pacientes simplesmente não conseguem dormir com o extrabucal e não cogitam usá-lo em ambientes sociais. Nós, profissionais de saúde, administramos a variabilidade das pessoas que tratamos e suas facilidades ou dificuldades de aderir a um tratamento qualquer, e temos que entender as dificuldades dos pacientes ao se submeterem a ele.

Esse fato tem sido negligenciado historicamente na literatura ortodôntica mundial. E há uma conduta na metodologia científica específica para gerir essa possível situação: a análise de intenção de tratar. Nessa conduta do pesquisador frente à casuística em análise, todos os pacientes incluídos no estudo no momento inicial serão acompanhados até o final da pesquisa. Os objetivos são evidenciar e relatar as razões da não-finalização da terapia por parte de cada um dos incluídos no estudo. Sempre que possível, esses casos devem até ser englobados na análise estatística. Essa conduta de pesquisa possibilita salientar com mais precisão a vivência do paciente quando se submete a uma terapia.

Falhas ou más interpretações de resultados de estudos têm, historicamente, acarretado indicações inadequadas de tratamento e sobretratamentos. E algumas patologias, tratadas pela Odontologia, têm sofrido mais do que outras com a dificuldade de se examinar a literatura científica. Um exemplo é a disfunção temporomandibular (DTM).

$\mathrm{O}$ artigo que recebe o selo do editor nessa edição - Ortodontia e disfunções temporomandibulares: o estado da arte -, do Dr. Paulo Conti, fornece uma ideia clara do estado do conhecimento sobre a DTM. Hoje, não é nebuloso e tampouco controverso o tratamento dessa condição. A leitura do trabalho proporcionará uma visão cristalina do relacionamento da Ortodontia com o tratamento dessa patologia.

Sejam críticos. Boa leitura.

Jorge Faber

Editor chefe

faber@dentalpress.com.br 